\title{
PENENTUAN HARGA OPSI DAN NILAI HEDGE MENGGUNAKAN PERSAMAAN NON-LINEAR BLACK-SCHOLES
}

\author{
Putu Ayu Deni ${ }^{\S 1}$, Komang Dharmawan ${ }^{2}$, G. K. Gandhiadi ${ }^{3}$ \\ ${ }^{1}$ Jurusan Matematika, Fakultas MIPA - Universitas Udayana [Email: ayudennni@gmail.com] \\ ${ }^{2}$ Jurusan Matematika, Fakultas MIPA - Universitas Udayana [Email: dharmawan.komang@gmail.com] \\ ${ }^{3}$ Jurusan Matematika, Fakultas MIPA - Universitas Udayana [Email: gandhiadigk@gmail.com] \\ ${ }^{\S}$ Corresponding Author
}

\begin{abstract}
Option are contracts that give the right to sell and buy the asset at a price and a certain period of time. In addition investors use option as a means of hedge against asset owned. Many methods are used to determine the price of option, one of them by using the Black-Scholes equation. But its use these in the assumption that the value for the constant volatility. On market assumption are not appropriates, so many researchers proposed using a volatility calculation option that is non-constant Black-Scholes equation modelled using the volatility is not constant in the range so as to produce a non-linear equation of Black-Scholes. In addition to determine the value of hedge ratio. On completions of this study, for the numerical solution of non-linear Black-Scholes equation using method of explicit finite difference scheme. Option use in research us a stock YAHOO!inc. as the underlying asset. The result showed that the price of the option is calculated using non-linear BlackScholes equation price close on the market. Therefore, it can produce hedge ration for a risk-free portfolio containing of the option and stock.
\end{abstract}

Keywords: Black-Scholes, Implied Volatility, non-linear Black-Scholes, hedge ration, finite difference methods, explicit scheme

\section{PENDAHULUAN}

Perkembangan investasi ditunjukan dengan munculnya berbagai macam alternatif instrumen investasi salah satunya adalah opsi. Opsi merupakan kontrak yang memberikan hak untuk membeli atau menjual aset pada harga dan jangka waktu tertentu. Opsi kerap digunakan oleh investor sebagai sarana untuk melakukan lindung nilai (hedging) terhadap aset yang dimiliki.

Terdapat berbagai cara yang dapat dilakukan dalam menghitung harga opsi, salah satu cara yang sering digunakan dalam dunia keuangan adalah model Black-Scholes. Dengan asumsi nilai volatilitas yang konstan, penerapan persamaan Black-Scholes ini dianggap belum sesuai dengan keadaan nyata dalam pasar keuangan. Pada pasar, nilai volatilitas memiliki kecenderungan tidak konstan. Sehingga model diturunkan menggunakan persamaan diferensial stokastik yang mengasumsikan diketahui adanya rentang dalam nilai volatilitas. Model tersebut mengubah asumsi bahwa volatilitas yang dianggap konstan diubah menjadi tidak konstan sehingga dapat ditentukan nilai opsinya. Selanjutnya akan ditentukan nilai hedge ratio menggunakan model Non-Linear Black-Scholes.

\section{TINJAUAN PUSTAKA}

A. Persamaan Klasik Black-Scholes

Dalam sebuah opsi terdapat nilai $V$ yang merupakan fungsi dari berbagai macam parameter, ditulis $V(S ; t ; \mu ; \sigma ; E ; T ; r)$. Dengan $S$, merupakan harga dari underlying asset; $t$ adalah waktu ; $\mu$ adalah drift dari $S ; E$ merupakan strike price; $T$ adalah batas waktu akhir opsi; dan $r$ bunga bebas risiko (Qiu \& Lorenz [3]). Asumsi dasar dari model klasik 
Black-Scholes mengikuti:

1. Tingkat suku bunga bebas risiko $r$ diketahui konstan, harga dari underlying asset mengikuti log-normal random walk

2. Drift dan volatilitas diketahui konstan

3. Saham tidak membayarkan dividen

4. Tipe opsi adalah opsi Eropa

Diberikan $\Pi$ merupakan portofolio dari nilai opsi dan $\Delta$ sebagai ukuran dari underlying asset

$$
\Pi=\mathrm{V}(\mathrm{S}, \mathrm{t})-\Delta \mathrm{S} .
$$

Dengan mengikuti asumsi bahwa harga $S$ dari underlying asset mengikuti log-normal random walk

$$
d \Pi=d V-\Delta d S .
$$

Perubahan harga saham $(S)$ dapat dimodelkan dengan menggunakan lemma Ito. Dimisalkan , $d V$ suatu peubah yang bergantung pada perubahan harga saham dan waktu. Apabila harga saham mengikuti persamaan (2) maka diperoleh

$$
d V=\frac{\partial V}{\partial t} d t+\frac{\partial V}{\partial S} d S+\frac{1}{2} \sigma^{2} S^{2} \frac{\partial^{2} V}{\partial S^{2}} d t
$$

Sehingga portofolio berubah menjadi

$$
d \Pi=\frac{\partial V}{\partial t} d t+\frac{\partial V}{\partial S} d S+\frac{1}{2} \sigma^{2} S^{2} \frac{\partial^{2} V}{\partial S^{2}} d t-\Delta d S .
$$

Pada persamaan (4) akan mengeleminasi risiko dengan menggunakan delta hedging, sehingga dipilih

$$
\Delta=\frac{\partial V}{\partial S}
$$

Dengan menggunakan persamaan (5) maka perubahan nilai portofolio menjadi

$$
d \Pi=\left(\frac{\partial V}{\partial t}+\frac{1}{2} \sigma^{2} S^{2} \frac{\partial^{2} V}{\partial S^{2}}\right) d t
$$

Dengan asumsi dari arbitrage-free market, perubahan $d \Pi$ akan sama dengan pertumbuhan dari $\Pi$ dalam asset yang mendapat bunga bebas risiko sehingga

$$
d \Pi=r\left(V-S \frac{\partial V}{\partial S}\right) d t
$$

Dengan mensubstitusi persamaan (6) ke dalam (7), didapat persamaan diferensial BlackScholes sebagai berikut

$$
\left(\frac{\partial V}{\partial t}+\frac{1}{2} \sigma^{2} S^{2} \frac{\partial^{2} V}{\partial S^{2}}\right) d t=r\left(V-S \frac{\partial V}{\partial S}\right) d t
$$

Selanjutnya kedua ruas dibagi dengan $d t$ sehingga dapat ditulis kembali dengan

$$
\frac{\partial V}{\partial t}+\frac{1}{2} \sigma^{2} S^{2} \frac{\partial^{2} V}{\partial S^{2}}+r S \frac{\partial V}{\partial S}-r V=0 .
$$

\section{B. Persamaan Non-Linear Black-Scholes}

Dalam perkembangannya model dari volatilitas yang tidak pasti sangat populer dan menarik (Zhang \& Wang [5]).

Asumsi yang mendasari model BlackScholes akan dimodifikasi dalam parameter volatilitas $(\sigma)$, dalam hal ini akan difokuskan pada asumsi volatilitas yang konstan. Pada volatilitas yang tidak konstan merupakan variabel stokastik yang tidak pasti. Terdapat dua cara untuk mencari nilai volatilitas yaitu dengan cara implied dan historical (Qiu \& Lorenz [3]).

Misalkan volatilitas terletak dalam rentang

$$
\sigma_{\min }<\sigma<\sigma_{\text {maks }}
$$

Akan diasumsikan bahwa volatilitas terdapat pada selang waktu tertentu yang akan memberikan keuntungan atau kerugian pada batas waktu jatuh tempo.

$$
\min _{\sigma_{\text {min }}<\sigma<\sigma_{\text {maks }}}(d \Pi)=r \Pi d t
$$

Selanjutnya diperoleh

$$
\begin{aligned}
& \min _{\sigma_{\min }<\sigma<\sigma_{\operatorname{maks}}}\left(\frac{\partial V}{\partial t}+\frac{1}{2} \sigma^{2} S^{2} \frac{\partial^{2} V}{\partial S^{2}}\right) d t= \\
& \left(V-S \frac{\partial V}{\partial S}\right) d t
\end{aligned}
$$

Sekarang akan diamati bahwa volatilitas akan dikalikan dengan gamma (Г) opsi tersebut. Oleh karena itu nilai $\sigma$ akan memberikan nilai minimum atau maksimum tergantung pada nilai gamma. Ketika gamma positif dipilih $\sigma$ menjadi nilai terendah $\sigma_{\min }$ dan ketika gamma bernilai negatif dipilih $\sigma$ menjadi nilai terbesar $\sigma_{\text {maks }}$. Diperoleh untuk kasus terburuk dengan fungsi $V_{\min }$ memenuhi

$$
\begin{aligned}
& \frac{\partial V_{\min }}{\partial t}+\frac{1}{2} \sigma(\Gamma)^{2} S^{2} \frac{\partial^{2} V_{\min }}{\partial S^{2}}+r S \frac{\partial V_{\min }}{\partial S}- \\
& r V_{\min }=0
\end{aligned}
$$




$$
\begin{gathered}
\text { dengan } \\
\Gamma=\frac{\partial^{2} V_{\min }}{\partial S^{2}} \\
\text { dan } \\
\sigma(\Gamma)= \begin{cases}\sigma_{\text {maks }} & \text { jika } \Gamma<0 \\
\sigma_{\text {min }} & \text { jika } \Gamma>0\end{cases}
\end{gathered}
$$

Untuk selanjutnya dapat diperoleh opsi terbaik dengan fungsi $V_{\text {maks }}$ dan range yang yang diperoleh memenuhi

$$
\begin{aligned}
& \frac{\partial V_{\text {maks }}}{\partial t}+\frac{1}{2} \sigma(\Gamma)^{2} S^{2} \frac{\partial^{2} V_{\text {maks }}}{\partial S^{2}}+r S \frac{\partial V_{\text {maks }}}{\partial S}- \\
& r V_{\text {maks }}=0 \\
& \text { dengan } \\
& \Gamma=\frac{\partial^{2} V_{\text {maks }}}{\partial S^{2}} \\
& \quad \text { dan } \begin{array}{ll}
\sigma_{\text {maks }} & \text { jika } \Gamma>0 \\
\sigma_{\text {min }} & \text { jika } \Gamma<0
\end{array}
\end{aligned}
$$

C. Solusi Numerik dengan Metode Beda Hingga

Pada kasus dengan satu aset akan dicari solusi numerik dengan menggunakan metode beda hingga. Dalam penelitian ini digunakan skema eksplisit dengan pendekatan pada persamaan diferensial Black-Scholes. Selanjutnya dapat ditulis persamaan BlackScholes sebagai berikut

$$
\frac{\partial V}{\partial t}+\frac{1}{2} \sigma^{2} S^{2} \frac{\partial^{2} V}{\partial S^{2}}+r S \frac{\partial V}{\partial S}-r V=0
$$

untuk

$r<T, S_{\min } \leq S_{r} \leq S_{\text {maks }}$

dengan syarat awal

$v\left(T, S_{T}\right)=\left(S_{T}-K\right)^{+}, 0 \leq r \leq T$

dan syarat batas

$$
v\left(r, S_{r}\right)=0, \quad 0 \leq r \leq T
$$

Selanjutnya persamaan (11) dapat ditulis sebagai

$\frac{\partial u}{\partial \tau}=\frac{\partial^{2} u}{\partial x^{2}}, \quad x_{\min }<x<x_{\text {maks }}, \quad 0<\tau<$ $\frac{1}{2} \sigma^{2} T$

dengan kondisi awal $u(0, x)=$ $\max \left(e^{\frac{1}{2}(k+1) x}-e^{\frac{1}{2}(k-1) x}, 0\right), \quad x_{\min } \leq x \leq$ $x_{\text {maks }}$
Selanjutnya didefinisikan titik grid sepajang jarak dan pada sumbu waktu

$$
\begin{array}{ll}
x_{i}=x_{\min }+i \Delta x & \text { untuk } i=1, \ldots N \\
t_{j}=j \Delta t & \text { untuk } j=1, \ldots M
\end{array}
$$

Persamaan (12) dapat ditulis dalam bentuk umum sebagai berikut

$\frac{v_{i}^{j}+v_{i}^{j-1}}{\Delta t}=\frac{v_{i+1}^{j}-2 v_{i}^{j}+v_{i-1}^{j}}{(\Delta x)^{2}}$

Dari persamaan (13), diperoleh

$v_{i}^{j-1}=\left(1-\frac{\Delta t}{(\Delta x)^{2}}\right) v_{i}^{j}+\frac{1}{2}\left(\frac{\Delta t}{(\Delta x)^{2}}\right)\left(v_{i+1}^{j+1}+\right.$ $\left.v_{i-1}^{j+1}\right)$

Untuk mencegah terjadinya osilasi, kondisi tersebut harus memenuhi

$$
\left(1-\frac{\Delta t}{(\Delta x)^{2}}\right) \geq 0
$$

\section{METODE PENELITIAN}

Jenis data yang digunakan dalam penelitian ini adalah data sekunder berupa data harga opsi dari Yahoo! Inc (YHOO) dengan periode pada waktu jatuh tempo pada bulan September 2015. Dalam penelitian ini mengambil data harga opsi dari http://finance.yahoo.com//

Metode pengumpulan data yang dilakukan dalam penelitian tugas akhir ini adalah dengan observasi data sekunder harga opsi. Disamping itu, studi literatur juga dilakukan yaitu membaca dan mencatat data serta informasi dari buku, jurnal, dan skripsi guna mendapatkan pengetahuan tambahan mengenai hal-hal yang terkait dalam penyusunan tugas akhir ini.

Langkah-langkah penentuan harga opsi dalam penelitian ini adalah sebagai berikut:

1. Mencari dan menentukan data opsi

Data yang digunakan adalah data harga opsi put dan call dalam periode Juli-Setember 2015. Data opsi tersebut dapat ditemukan dalam alamat web

http://finance.yahoo.com/q/op?s=YHOO+O ptions.

2. Menentukan parameter dan variabel.

Pada penelitian ini akan digunakan implied volatilitas sebagai parameter volatilitas, yang terdapat pada daftar harga opsi. Langkah selanjutnya mencari variabel- 
variabel yang diperlukan untuk menghitung opsi, yaitu $S$ (harga saham awal), $T$ (waktu jatuh tempo opsi), $K$ (harga eksekusi opsi), $r$ (suku bunga bebas risiko), dan harga maksimum (S plus) dan minimum (S minus) yang diperoleh dari data opsi.

3. Solusi numerik untuk persamaan diferensial Black-Scholes tak linier.

Dalam penelitian ini persamaan diferensial akan diselesaikan menggunakan skema eksplisit, dengan kondisi yang bersyarat yaitu

$\sigma\left(\Gamma^{j+1}\right)= \begin{cases}\sigma_{\operatorname{maks}}{ }^{2} & \text { jika } \Gamma^{j+1} \geq 0 \\ \sigma_{\min }{ }^{2} & \text { jika } \Gamma^{j+1} \leq 0\end{cases}$

dengan gamma $(\Gamma)$

$$
\Gamma=\frac{v_{i+1}^{j-1}-2 v_{i}^{j-1}+v_{i-1}^{j-1}}{(\Delta x)^{2}}
$$

Skema ini akan diselesaikan dengan algoritma dari solusi numerik pada persamaan (11) dan (12) (Dharmawan, K. [1])

$$
\text { Untuk } i=1, \ldots, M \text { dan } j=1, \ldots, N
$$

(1) Masukkan nilai awal $\left\{v_{0}^{j}\right\}_{j=0}^{N-1}$

(2) Definisikan titik grid dengan melakukan langkah-langkah berikut untuk $i=1$

i. Masukkan nilai $v_{i}^{0}=0$

ii. Lakukan langkah berikut untuk $j=1$ sampai $N-2$

iii. Cari nilai $\operatorname{grad}_{i}^{j-i}$ dengan $\operatorname{grad}_{i}^{j-i}=v_{i-1}^{j-2}-2 v_{i-1}^{j+1}+v_{i-1}^{j}$

iv. Jika $\operatorname{grad}_{i}^{j-i} \leq 0$ maka dipilih nilai $\sigma=\sigma_{\text {min }}$ dengan $\alpha=0.5 \sigma^{2} \Delta t / \Delta x^{2}$, jika tidak maka dipilih nilai $\sigma=\sigma_{\max }$ dengan nilai $\alpha=0.5 \sigma^{2} \Delta t / \Delta x^{2}$

v. Selanjutnya hitung nilai

$$
\begin{aligned}
& \mathrm{v}_{i}^{j+i}=(1-2 \alpha) v_{i-1}^{j+1}-\alpha v_{i-1}^{j+2}+ \\
& \alpha v_{i-1}^{j}
\end{aligned}
$$

(3) Lakukan langkah yang sama seperti langkah no 2 dengan $i=2$ sampai dengan $M-1$

4. Mencari hedge ratio

Dalam mencari hedge akan digunakan turunan kedua dari persamaan (5) dengan mengikuti algoritma berikut.
Untuk menghitung nilai hedge ratio diselesaikan mengikuti langkah berikut untuk $i=1$

i. Lakukan langkah berikut untuk $j=$ $2,3, \ldots, N$

$$
\Delta_{i, j}=\frac{v_{i, j}-v_{i, j-1}}{x_{j}-x_{j-1}}
$$

ii. Lakukan langkah diatas untuk $i=$ 2 sampai dengan $M$

\section{HASIL DAN PEMBAHASAN}

\section{A. Implementasi Persamaan Non-linear Black-Scholes}

Pada penelitian ini digunakan volatilitas yang tidak konstan. Pada persamaan klasik Black-Scholes dimodelkan kedalam bentuk persamaan non-linear Black-Scholes dengan menggunakan pendekatan solusi numerik. Solusi numerik diselesaikan menggunakan metode beda hingga dengan skema eksplisit. Hasil implementasi berikut menggunakan input yaitu, $\sigma_{\text {min }}, \sigma_{\text {maks }}, S, T, K, r, N, M, S$ maks dan $S$ min. Dengan menggunakan algoritma, diperoleh grafik sbagai berikut

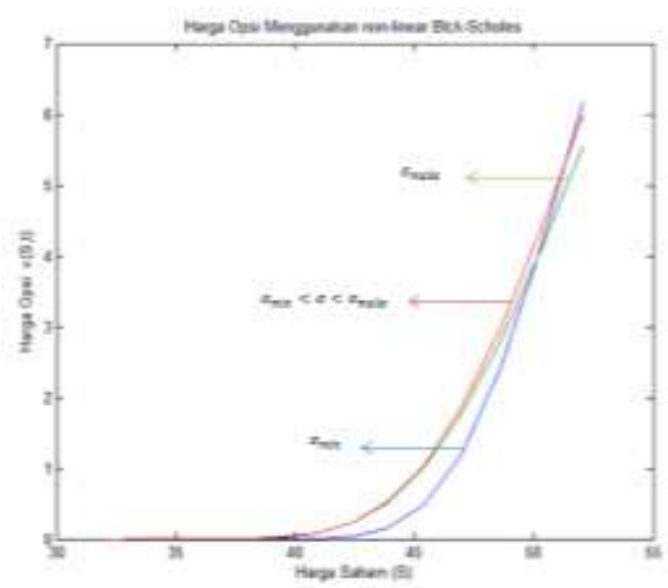

Pada gambar di atas dengan harga tebus $(\mathrm{K})$ sebesar 47,00, digunakan nilai opsi dengan volatilitas yang berada pada rentang $\sigma_{\min }<$ $\sigma<\sigma_{\text {maks }}$ dengan nilai sebesar 6,032. Dari hasil diatas, dengan harga saham yang ditawarkan sebesar 52 dan para pemegang opsi menyepakati harga tebus atau harga kesepakatan sebesar 47,00 maka diperoleh harga opsi sebesar 6,032. Harga ini dipilih karena harga tersebut didapat dengan 
menggunakan volatilitas tidak konstan yang sesuai dengan keadaan pasar.

\section{B. Implementasi dalam Penentuan Nilai Hedge Ratio}

Hedge ratio adalah tingkat perubahan ratarata nilai opsi terhadap harga saham. Berdasarkan definisi dan dengan menggunakan model Black-Scholes didapat rasio lindung nilai terdapat pada persamaan (5). Dengan nilai $v$ adalah total dari nilai opsi dalam portofolio, yaitu jumlah semua nilai opsi dalam portofolio. Hedge ratio menujukkan bahwa ada kemungkinan membuat portofolio yang bebas resiko yang terdiri dari opsi dan saham. Nilai hedge ratio akan hitung menggunakan persamaan non-linear Black-Scholes,yang akan diselesaikan dengan algortima sehingga diperoleh grafik sebagai berikut

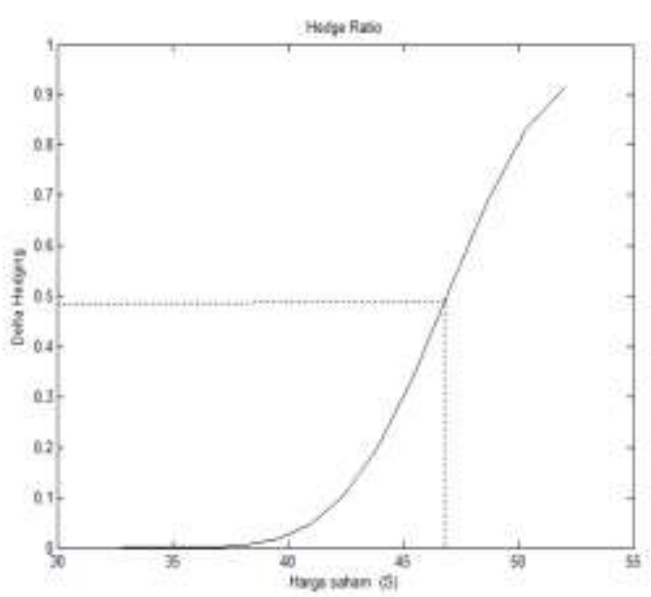

Dari gambar diatas menunjukkan bahwa harga opsi dengan delta hedging diperoleh sebesar 0,496 sehingga diperoleh besaran rasio hedge utuk opsi 49,6\% sedangkan untuk saham $50,4 \%$ sehingga terbentuk portofolio yang terdiri dari aset yang berisiko dan yang bebas risiko.

\section{KESIMPULAN DAN SARAN}

\section{A. Kesimpulan}

Perhitungan opsi menggunakan persamaan non-linear Black-Scholes menghasilkan harga opsi yang ideal karena sesuai dengan keadaan pasar yang bergerak dengan volatilitas yang tidak konstan. Dengan menggunakan volatilitas antara $20 \%$ dan $30 \%$ diperoleh harga opsi sebesar 6,032.

Dari perhitungan untuk nilai hedge ratio diperoleh rasio untuk portofolio yaitu proporsi untuk underlying asset dan opsi sehingga diperoleh portofolio yang bebas risiko dengan rasio sebesar 49,6\% dan underlying asset 50,4\% pada harga tebus sebesar 47.

\section{B. Saran}

Pada penelitian ini menggunakan opsi dengan tipe Eropa, untuk pengembangan penelitian diharapkan dapat menggunakan opsi dengan tipe Amerika dan tipe Barier. Pada penghitungan harga opsi dengan tipe Eropa dapat disertakan deviden.

\section{DAFTAR PUSTAKA}

[1] Dharmawan, K. (2005). Supperreplication Method for Multi-asset Barrier Options. Ph.D. Thesis. University of New South Wales Library, Sydney.

[2] Husnan, S. (1998). Dasar-Dasar Teori Portofolio. Yogyakarta: UPP AMP YKPM.

[3] Qiu, Y., \& Lorenz, J. (2009). A Non-Linier Black-Scholes Equation. Int. J. Business Perform and Supply Chain Modelling, vol.1, pp.33-40.

[4] Willmot, P. (1998). The Theory and Practice of Financial Engineering. New York: John Wiley \& Sons.

[5] Zhang, K., \& Wang, S. (2009). A Computational Scheme for Uncertain Volatility Model in Option Pricing. IMACS, 1754-1767. 